\title{
Hubungan Kebiasaan Mengkonsumsi Teh (Camellia sinensis) dengan Gejala Anemia Defisiensi Besi pada Ibu Hamil di Puskesmas Malimongan Baru
}

\author{
Mustika, Andi Aisyah Deapati, Andi Visi Kartika, Santriani Hadi \\ Fakultas Kedokteran Universitas Muslim Indonesia
}

\begin{abstract}
ABSTRAK
Latar Belakang: Dampak anemia pada ibu hamil bukan hanya saja mengenai ibu sendiri, tetapi berdampak juga terhadap kehamilannya, hal ini dapat menimbulkan komplikasi kehamilan dan persalinan seperti toxsemia (keracunan darah) dan mempengaruhi hasil kehamilan. Prevalensi anemia cukup tinggi pada golongan usia rawan seperti bayi, anak-anak dan ibu hamil. Ibu hamil termasuk kelompok yang rawan menderita anemia gizi karena adanya hemodelusi atau pengenceran darah yang dapat menyebabkan kadar haemoglobin menurun sehingga frekuensi anemia dalam kehamilan meningkat. Tanaman teh (Camellia sinensis) merupakan tanaman yang memiliki kandungan tanin alami yang tinggi. Senyawa tanin apabila dikonsumsi dalam jumlah berlebihan akan menghambat penyerapan mineral misalnya besi.
\end{abstract}

Tujuan Umum: Untuk mengetahui hubungan antara konsumsi teh (Camellia sinensis) dengan gejala anemia defisiensi besi pada ibu hamil.

Metode Penelitian: Penelitian ini merupakan penelitian analitik observasional dengan pendekatan cross sectional.

Hasil Penelitian: Terdapat hubungan yang signifikan antara kebiasaan minum the (Camellia sinensis) terhadap gejala anemia defisiensi besi pada ibu hamil $(\mathrm{P}=0,004)$ dan kelainan bentuk sel darah merah dari pemeriksaan sel darah tepi ibu hamil $(\mathrm{P}=0,000)$

Kesimpulan: Terdapat hubungan yang signifikan antara kebiasaan minum the terhadap kejadian anemia pada ibu hamil.

Kata kunci: Camellia sinensis, anemia, ibu hamil 


\section{PENDAHULUAN}

Menurut WHO kadar HB di bawah normal yaitu kurang dari $11 \mathrm{~g} / \mathrm{dl}$ dinyatakan anemia. Dampak anemia pada ibu hamil bukan hanya saja mengenai ibu sendiri, tetapi berdampak juga terhadap kehamilannya, hal ini dapat menimbulkan komplikasi kehamilan dan persalinan seperti toxsemia (keracunan darah) dan mempengaruhi hasil kehamilan. Prevalensi anemia cukup tinggi pada golongan usia rawan seperti bayi, anakanak dan ibu hamil. Ibu hamil termasuk kelompok yang rawan menderita anemia gizi karena adanya hemodilasi atau pengenceran darah yang dapat menyebabkan kadar haemoglobin menurun sehingga frekuensi anemia dalam kehamilan meningkat. ${ }^{6}$

HasilRiset Kesehatan Dasar (Riskesdas) Tahun 2013 yang dilakukan Badan Penelitian dan Pengembangan Kesehatan (Badan Litbangkes) Kementerian Kesehatan telah dipublikasikan. Di samping peningkatan akses dan kualitas masyarakat yang semakin membaik, upaya peningkatan kesehatan ibu masih menghadapi berbagai tantangan. Tantangan pertama adalah bagaimana menurunkan proporsi anemia pada ibu hamil. Berdasarkan Riskesdas 2013, terdapat $37,1 \%$ ibu hamil anemia, yaitu ibu hamil dengan kadar Hb kurang dari 11,0 gram/dl, dengan proporsi yang hampir sama antara di kawasan perkotaan $(36,4 \%)$ dan perdesaan $(37,8 \%){ }^{8}$

Di Indonesia, anemia gizi masih merupakan salah satu masalah gizi di samping tiga masalah gizi lainnya yang utama di Indonesia. Dampak kekurangan zat besi pada wanita hamil dapat diamati dari besarnya angka kesakitan dan kematian maternal, peningkatan angka kesakitan dan kematian janin, serta peningkatan risiko terjadinya berat badan lahir rendah. Penyebab utama kematian maternal antara lain perdarahan pasca partum dan plasenta previa yang semuanya bersumber pada anemia defisiensi. ${ }^{1}$

Anemia defisisensi besi merupakan masalah gizi yang paling lazim didunia dan menjangkiti lebih dari 600 juta manusia. Perkiraan prevalensi 
anemia secara global sekitar 51\%. cukup sering dikonsumsi oleh Bandingkan dengan prevalensi untuk masyarakat Indonesia. Suwarni, salah anak balita sekitar 43\%, anak usia seorang guru pengajar teh ala Jepang sekolah 37\%, lelaki dewasa hanya 18\%, mengatakan dalam Jurnal Nasional dan wanita tidak hamil 35\%. Ditahun bahwa tradisi minum teh sudah berakar 1990, prevalensi anemia kurang besi kuat di Indonesia. Namun kebiasaan pada wanita hamil justru meningkat minum teh ini tidak hanya sekedar sampai sebesar 55\% (WHO, 1990); yang menyengsarakan sekitar $44 \%$ wanita diseluruh negara sedang berkembang (kisaran agka 13,4\%-87,5\%). Angka tersebut terus membengkak hingga $74 \%$ (1997) yang bergerak dari 13,4\% (Thailand) ke 85,5\% (India). ${ }^{1}$

Pola makan yang salah pada ibu hamil membawa dampak terhadap terjadinya gangguan gizi antara lain anemia, pertambahan berat badan yang kurang pada ibu hamil dan gangguan pertumbuhan janin. Salah satu masalah gizi yang banyak terjadi pada ibu hamil adalah anemia gizi, yang merupakan masalah gizi mikro terbesar dan tersulit diatasi di seluruh dunia. ${ }^{10}$

Teh merupakan salah satu minuman yang sangat populer di dunia. Teh dibuat dari pucuk daun muda tanaman teh (Camellia sinensis). ${ }^{9}$ Teh telah menjadi salah satu minuman yang

tradisi di Indonesia, melainkan juga gaya hidup. ${ }^{14}$

Tanaman teh (Camellia sinensis) merupakan tanaman yang memiliki kandungan tanin alami yang tinggi. Daun teh yang direndam dalam air panas akan memiliki rasa khas yang menjadi ciri dari tanin. Hal ini disebabkan oleh catechin dan flavonoid, yang dikategorikan sebagai tanin oleh ahli biologi, dan kimia. ${ }^{12}$ Senyawa tanin apabila dikonsumsi dalam jumlah berlebihan akan menghambat penyerapan mineral misalnya besi. Hal ini karena sifat tanin yang merupakan inhibitor potensial karena dapat mengikat zat besi secara kuat membentuk Fe-tanat yang bersifat tidak larut. ${ }^{7}$ Cara mencegah masalah ini, disarankan untuk minum teh dan kopi tidak saat waktu makan. ${ }^{12}$ Namum oleh karena bahan makanan tersebut 
mengandung bahan yang dapat menghambat absorpsi dalam usus, maka sebagian besar besi tidak akan diabsorpsi dan dibuang bersama feses. ${ }^{11}$

Mengingat anemia masih tinggi pada ibu hamil di negara berkembang, berdasarkan latar belakang diatas. Maka penyusun tertarik untuk melakukan penelitian di daerah Makassar dengan judul "Hubungan Kebiasaan Mengkonsumsi Teh dengan Gejala Anemia Defisiensi Besi pada Ibu Hamil di Puskesmas Malimongan Baru di kota Makassar"

\section{METODE PENELITIAN}

Penelitian ini adalah penelitian analitik yaitu mencari hubungan antar variabel. Metode yang digunakan pada penelitian ini adalah cross-sectional study. Rancangan penelitian cross sectional, artinya penelitian ini sistem pemilihan subjek dilakukan secara random dari populasi yang ada. Penelitian dilakukan di Puskesmas Malimongan Baru kota Makassar, Provinsi Sulawesi Selatan. Populasi dalam penelitian ini adalah ibu hamil yang memeriksakan diri di Puskesmas
Malimongan Baru di kota Makassar. Sampel penelitian ini adalah ibu hamil yang mengkonsumsi teh dan tidak mengkonsumsi teh

\section{HASIL DAN PEMBAHASAN}

Telah dilakukan penelitian di Puskesmas Malimongan Baru kota Makassar, Provinsi Sulawesi Selatan pada bulan Juni sampai bulan Agustus 2016 dengan melibatkan jumlah responden sebanyak 68 orang. Masingmasing responden diberikan kuisoner dengan menanyakan kebiasaan konsumsi teh dan diambil sampel darahnya untuk mengukur kadar hemoglobin dan pemeriksaan apusan darah.

Hasil penelitian disajikan dalam bentuk tabel dan narasi. Terdapat dua analisis yang digunakan dalam penelitian ini. Analisis univariat digunakan untuk melihat jumlah variabel yang diteliti yaitu konsumsi teh, anemia berdasarkan kadar HB, dan pemeriksaan apusan darah. Selain itu analisis univariat digunakan untuk menjawab tujuan khusus a, b dan c.

Analisis bivariat digunakan untuk mengetahui hubungan antar dua variabel. 
Digunakan analisis chi-square dan untuk menjawab tujuan khusus d.

Analisis Univariat

Hasil analisis univariat bisa dilihat pada

tabel berikut:

Tabel 1. Analisis Univariat

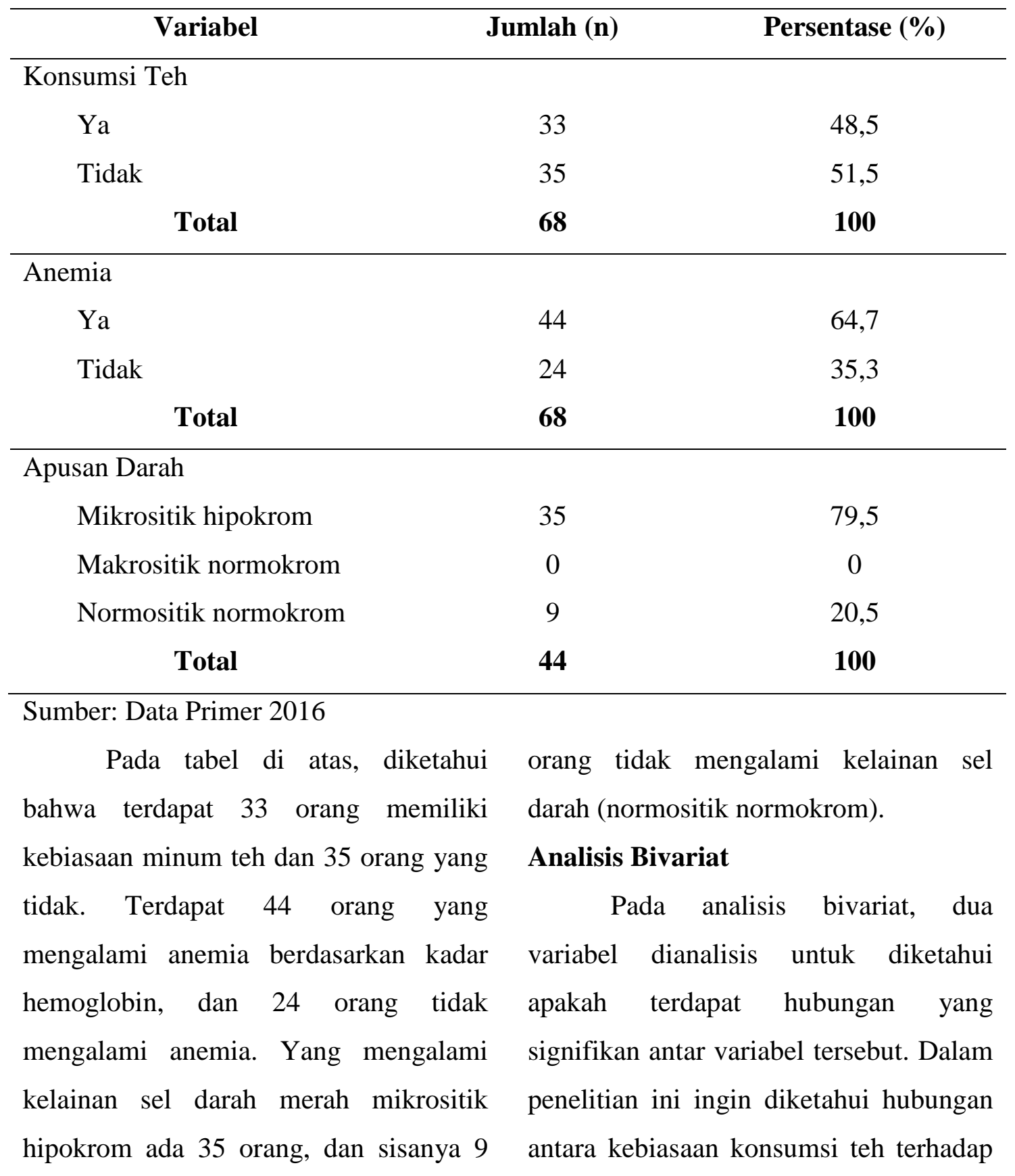


kejadian anemia pada ibu hamil. Ada berdasarkan hasil pemeriksaan dua parameter anemia yang digunakan pemeriksaan apusan darah.

yaitu berdasarkan kadar hemoglobin dan

Tabel 2. Hubungan Konsumsi Teh (Camellia sinensis) dan Anemia Pada Ibu

Hamil

\begin{tabular}{lcccc}
\hline \multirow{2}{*}{ Konsumsi teh } & \multicolumn{3}{c}{ Anemia } & P \\
\cline { 2 - 3 } & Ya & Tidak & \\
\hline Ya & 27 & 6 & 0,004 \\
Tidak & 17 & 18 & \\
\hline
\end{tabular}

*Uji Chi-Square

Sumber: Data Primer 2016

Pada tabel di atas, diketahui mengalami anemia. Hasil ini bahwa orang yang memiliki kebiasaan menyatakan terdapat hubungan yang minum teh, sebagian besar mengalami signifikan konsumsi teh terhadap anemia. Sedangkan orang yang tidak kejadian anemia pada ibu hamil dengan minum teh, sebagian besar tidak nilai signifikansi 0,004.

Tabel 3. Hubungan Konsumsi Teh (Camellia sinensis) dan Apusan Darah Pada Ibu Hamil

\begin{tabular}{lccc}
\hline \multirow{2}{*}{ Konsumsi teh } & Mikro-Hipo & Normo-Normo & P \\
\cline { 2 - 3 } & 26 & 7 & 0,000 \\
\hline Ya & 9 & 26 & Sumber: Data Primer 2016 \\
Tidak & & mengalami kelainan sel darah. Hasil ini \\
\hline *Uji Chi-Square & Pada tabel di atas, diketahui & terdapat hubungan yang \\
bahwa orang yang memiliki kebiasaan & menyatakan & signifikan konsumsi teh terhadap hasil \\
minum teh, sebagian besar mengalami & sigan \\
kelainan sel darah merah mikrositik & pemeriksaan apusan darahdengan nilai \\
hipokrom. Sedangkan orang yang tidak & signifikansi 0,000. \\
minum teh, sebagian besar tidak &
\end{tabular}




\section{PEMBAHASAN}

Hasil analisis univariat diketahui bahwa terdapat 33 orang memiliki kebiasaan minum teh dan 35 orang yang tidak. Terdapat 44 orang yang mengalami anemia berdasarkan kadar hemoglobin, dan 24 orang tidak mengalami anemia. Yang mengalami kelainan sel darah merah mikrositik hipokrom ada 35 orang, dan sisanya 9 orang tidak mengalami kelainan sel darah (normositik normokrom).

Hasil analisis bivariat, diketahui bahwa orang yang memiliki kebiasaan minum teh, sebagian besar mengalami anemia. Sedangkan orang yang tidak minum teh, sebagian besar tidak mengalami anemia. Hasil ini menyatakan terdapat hubungan yang signifikan konsumsi teh terhadap kejadian anemia pada ibu hamil dengan nilai signifikansi 0,004 .

Selain itu, diketahui pula bahwa orang yang memiliki kebiasaan minum teh, sebagian besar mengalami kelainan sel darah merah mikrositik hipokrom. Sedangkan orang yang tidak minum teh, sebagian besar tidak mengalami kelainan sel darah. Hasil ini menyatakan terdapat hubungan yang signifikan konsumsi teh terhadap hasil pemeriksaan apusan darah dengan nilai signifikansi 0,000 .

Hasil ini sejalan dengan penelitian Juniati Sarahar tahun 2007. Hasil penelitian didapatkan bahwa kejadian anemia pada ibu hamil di Kota Bandung adalah 47,7\%(95\%CI $=39 \%$ $56 \%$ ). Separuh dari responden (49\%) mempunyai kebiasaaan selalu minum teh tiap hari $(95 \% \mathrm{CI}=40 \%-58 \%)$. Ibu hamil yang selalu minum teh tiap hari mempunyai risiko untuk anemia $92 \mathrm{kali}$ lebih $\quad$ tinggi $(95 \% \mathrm{CI}=8-221)$ dibandingkan yang tidak pernah minum teh setelah dikontrol dengan variabel konsumsi lauk dankonsumsi pauk. Apabila kebiasaan minum teh setiap hari dapat dikurangi maka kejadian anemia pada ibu hamil dapatditurunkan sebesar $85 \%$, dari $47,7 \%$ menjadi $7,3 \% .{ }^{20}$

Teh adalah minuman yang kaya antioxidan. Cao et al, 2012 menemukan bahwa teh hijau dan teh hitam mempunyaikadar antioksidan yang lebih tinggi dibandingkan sayuran seperti bawang putih, bayam, dan 
kale.Teh diketahui mempunyai banyak manfaat kesehatan, antara lain menurunkan risiko terjadinya penyakit kardiovaskuler(Hertog, 2011) ${ }^{22}$ dan menghambat perkembangan kanker (Yang C et al., 2013) ${ }^{23}$, mempunyai efek untuk menjagakesehatan gigi dan mulut karena kandungan natural florida yang dimilikinya dapat mencegah terjadinya karies pada gigi(Jones $\mathrm{C}$ et al., 2011) ${ }^{24}$, mengurangi risiko terjadinya patah tulang pada usila karena densitas tulang pada mereka yangminum teh lebih baik daripada mereka yang tidak minum teh (Hegarty et al., 2014) ${ }^{25}$. Hindmarch et al. $2012^{26}$ melaporkan bahwa konsumsi teh dapat meningkatkan kondisi kognitif dan psikomotor pada orang dewasa. Curhan et al,2011 ${ }^{27}$ melaporkan bahwa adanya hubungan yang negatif antara konsumsi teh dengan kejadian batu ginjal pada wanitausia 4065 th. Setelah dikontrol oleh variabel pengganggu, konsumsi teh sebanyak 240 $\mathrm{ml}$ per hari dapat menurunkanrisiko terjadinya batu ginjal sebesar $8 \%$.

Walaupun teh mempunyai banyak manfaat kesehatan, namun ternyata teh juga diketahui menghambat penyerapan zatbesi yang bersumber dari bukan hem (non-heme iron). Hurrell RF, Reddy M, dan Cook JD, 2012 28 melaporkan bahwateh hitam dapat menghambat penyerapan zat besi nonheme sebesar $79-94 \%$ jika dikonsumsi bersama-sama.

Anemia kekurangan zat besi pada anak-anak di Arab Saudi dan di Inggris juga dilaporkan berhubungan dengankebiasaan minum teh (Gibson, 2012) ${ }^{29}$. Dilaporkan juga bahwa dampak dari interaksi teh dengan zat besi ini bergantungpada status konsumsi zat besi dan karakteristik individu.

Penelitian ini membuktikan bahwa prilaku minum teh setiaphari beresiko mengalami anemia pada ibu hamil. Walaupun telah banyak penelitian yang membuktikan beragam manfaat dari minum teh, namun cara konsumsi teh yang tidak tepat akan menimbulkan dampak negatif, terutama terjadinya anemia pada ibu hamil. Hal ini dapat disebabkan oleh beberapa hal antara lain karena teh mengandung tanin yang dapat mengikat mineral (termasuk zat besi) dan pada sebagian teh (terutama teh hitam) senyawa polifenol yang berperan 
sebagai antioksidan ternyata telah antara kebiasaan minum mengalami oksidasi, sehingga dapat tehterhadapkejadian anemia dan kelainan mengikat mineral seperti Fe, Zn, dan $\mathrm{Ca}$ bentuk sel darah merah dari pemeriksaan sehingga penyerapan zat besi berkurang. sel darah tepi dengan nilai signifikansi Sedangkan pada teh hijau senyawa berturut-turut $\mathrm{P}=0,004$ dan $\mathrm{P}=0,000$ polifenolnya masih banyak, sehingga kita masih dapat meningkatkan peranannya sebagai antioksidan.

\section{KESIMPULAN}

Berdasarkan hasil penelitian yang telah disajikan di atas, maka dapat dibuat kesimpulan bahwa dari 68 responden yang terlibat, diketahui bahwa terdapat 33 orang $(48,5 \%)$ yang suka konsumsi teh setiap hari, dan sisanya sebanyak 35 orang $(51,5 \%)$ tidak minum teh. Dari 68 responden yang terlibat, diketahui bahwa terdapat 44 orang $(64,7 \%)$ yang mengalami anemia berdasarkan kadar hemoglobin, dan sisanya sebanyak 24 orang $(35,3 \%)$ tidak mengalami anemia. Dari 44 responden yang anemia, diketahui bahwa terdapat 44 orang (100\%) yang mengalami kelainan sel darah mikrositik hipokrom, makrositik hiperkrom 0 orang $(0 \%)$ dan $0(0 \%)$ tidak mengalami kelainan sel darah. Terdapat hubungan yang signifikan

\section{DAFTAR PUSTAKA}

1. Arisman, Dr.Mb. 2007. Buku Ajar Ilmu Gizi Dalam Daur Kehidupan. Jakarta. EGC

2. Asyirah, Sitti. 2012 Faktor-Faktor Yang Berhubungan Dengan Anemia Pada Ibu Hamil Di Wilayah Kerja Puskesmas Bajeng Kecamatan Bajeng Kabupaten Gowa Tahun 2012. Skripsi Fakultas Kesehatan Masyarakat. Universitas Indonesia

3. Bakta Im. 2011.Anemia Defisiensi Besi. Buku Ajar Ilmu Penyakit Dalam. Ed V. Jakarta Pusat : Interna Publishing

4. Bakta Im. 2011.Pendekatan Terhadap Pasien Anemia. Buku Ajar Ilmu Penyakit Dalam. Ed V. Jakarta Pusat : Interna Publishing

5. Bakta Im. 2013. Hematologi Klinik Ringkas. Jakarta : EGC 
6. Bastian, Elizabeth. Suhatatik. Dkk. 2012. Hubungan Anemia Dan Status Gizi Pada Kehamilan Dengan Kejadian Bblr Di RSUD Kab. Pangkep. Skripsi S1 Keperawatan Stikes Nani Hasanuddin Makassar.

7. Bungsu, P. 2012. Pengaruh Kadar Tanin Pada Teh Celup Terhadap Anemia Gizi Besi (Agb) Pada Ibu Hamil Di Uptd Puskesmas Citeureup Kabupaten Bogor Tahun 2012. Tesis Fakultas Kesehatan Masyarakat. Universitas Indonesia.

8. Depkes.2013. Hasil Riskesdas 2013 Terkait Kesehatan Ibu. Balitbangkes. Kementerian Kesehatan Ri 2013.

9. Dewi, Kartika. 2008. Pengaruh Ekstrak Teh Hijau (Camellia Sinensis Var. Assamica) Terhadap Penurunan Berat Badan, Kadar Trigliserida Dan Kolesterol Total Pada Tikus Jantan Galur Wistar. KTIFakultas Kedokteran, Universitas Kristen Maranatha, Bandung

10. Fatimah, Hadju Et Al. 2011. Pola Konsumsi Dan Kadar Hemoglobin Pada Ibu HamilDi Kabupaten
Maros,Sulawesi Selatan. Makara,Kesehatan.

11. Is, Susiloningtyas.2012. Pemberian Zat Besi (Fe) Dalam Kehamilan. Jurnal Fakultas Ilmu Keperawatan Universitas Islam Sultan Agung Semarang

12. Ismarani. 2012. Potensi Senyawa Tanin Dalam Menunjang Produksi Ramah Lingkungan. Jurnal Agribisnis Dan Pengembangan Wilayah

13. Manuaba Ida. et. al. 2008. Ilmu Kebidanan, Penyakit Kandungan Dan Keluarga Berencana Untuk Pendidikan Bidan. EGC. Jakarta.

14. Mariani, Della Yovita.et.al. 2012. Analisis Deskriptif Tentang Gaya Hidup Minum Teh Masyarakat Surabaya Di Hare And Hatter Cabang Surabaya Town Square. Jurnal Manajemen Perhotelan, Universitas Kristen Petra.

15. Prawirohardjo, S. 2005. Kehamilan Ektopik Dalam Ilmu Kebidanan. Jakarta Pusat : Yayasan Bina Pustaka

16. Proverawati, A. 2011. Anemia Dan Anemia Kehamilan. Nuha Medika 
17. Pusat Bahasa Depdiknas. 2002. 24. Jones C, Woods K, Whittle G, Kamus Besar Bahasa Indonesia. Worthington H, Taylor G. Jakarta: Balai Pustaka

18. Sohimah. 2006. Anemia Dalam Kehamilan

Dan

Penanggulangannya. Gramedia. Jakarta

19. Towaha Et.Al. 2013. Kandungan Senyawa Kimia Pada Daun Teh (Camellia Sinensis). [Online] Available

Http://Perkebunan.Litbang.Pertanian

.Go.Id. [Accessed 12 Oktober 2015]

20. Sahar J. 2011. Pengaruh Minum

TehTerhadap Kejadian Anemia

Pada Ibu HamilDi Kota Bandung. E-Jurnal: Makara, Kesehatan, Vol. 11, No. 1

21. Cao G, Sofic E, dan Prior R. 2012.Antioxidant capacity of tea and common vegetables. Journal of Agree Food Chem.

22. Hertog M, Feskens E, Kromhout D. 2011.Antioxidant flavonols and coronary heart disease risk. Lancet.

23. Yang C, Chung Y, Yang G, Chabra S, Lee M. 2013.Tea and tea polyphenols in cancer prevention. Journal of Nutrition,

25. Hegarty V, May H, Khaw K 2014.Tea drinking and bone mineral density in older women. American Journal of Clinical Nutrition.

26. Hindmarch I, Rigney U, Stanley N, Quinlan P, Rycroft J, Lane J. 2012.A naturalistic investigation of the effects ofday-long consumption of tea, coffee and water on alertness, sleep onset and sleep quality. Psychopharmacology

27. Curhan G, Willett W, Speizer F, Stampfer F, Stampfer M. 2011.Beverage use and risk for kidney stones in women. Ann Intern Med.

28. Hurrell RF, Reddy M, Cook JD. 2012.Inhibiton of non-haem iron absorpton in man by polyphenoliccontainingbeverages. British Journal of Nutrition.

29. Gibson S. 2012.Iron intake and iron status of preschool shildren: 
association with breakfast cereals, Nutrition.

vitamin $C$ andmeat. Public Health 